\title{
Analisis Incident Management E-Court Pada Pengadilan Negeri Salatiga Menggunakan Framework ITIL V4
}

\author{
Jessica Adelila Ayuh*1 ${ }^{*}$, Hanna Prillysca Chernovita ${ }^{2}$ \\ ${ }^{1,2}$ Universitas Kristen Satya Wacana; Jl. Diponegoro No.52-60, Salatiga, \\ Kec. Sidorejo, Kota Salatiga, Jawa Tengah, 50711, (0298) 321212 \\ ${ }^{3}$ Program Studi Sistem Informasi, FTI UKSW, Salatiga \\ e-mail: *1682017011@ student.uksw.edu, ${ }^{2}$ hanna.chernovita@uksw.edu
}

\begin{abstract}
Abstrak
Pada organisasi SI TI merupakan bagian yang terpenting dalam kegiatan pelayanan dan kelancaran aktivitas operasional bisnis, Pengadilan Negeri Salatiga menggunakan E-Court aplikasi dari Mahkamah Agung yang difungsikan sebagai wadah pelayanan masyarakat untuk penanganan perkara, yakni pendafttaran perkara (e-filing), pembayaran panjar online (ePayment), pemanggilan elektronik (e-Summons) dan persidangan elektronik (e-Litigation). Pada PN Salatiga dalam penanganan insiden masih belum menggunakan acuan yang digunakan untuk pengelolaaan insiden secara terstruktur, sehingga proses penyelesaian tidak berjalan secara optimal. Jika terdapat insiden pada salah E-Court, akan berdampak pada kepuasan layanan terhadap pengguna. Oleh karna itu PN Salatiga membutuhkan incident management dengan pengelolaan insiden yang optimal sesuai dengan standar. Kerangka kerja yang digunakan yaitu ITIL V4 dengan komponen utamanya adalah service value system dan 4 dimensi. Dimensi keempat adalah value stream dan process yang mana pada value stream memungkinkan memiliki gambaran untuk melakukan perbaikan terus menerus. Metode penelitian menggunakan pendekatan kualitatif yang dapat mempermudah melihat kondisi incident management pada PN Salatiga. Hasil penelitian berupa rancangan SOP (Standard Operating Procedure) sebagai acuan untuk pengelolaan incident yang terjadi, yang berkaitan pada proses incident management ITIL, service value chain pada incident management ITIL 4 dalam deliver dan support untuk memberikan kontribusi dan layanan yang signifikan pada incident management PN Salatiga.
\end{abstract}

Kata kunci-Incident Management, ITIL V4, Service Value System, SOP, Value Stream

\begin{abstract}
In the IS IT organization is the most important part in service activities and smooth business operational activities, PN Salatiga uses the E-Court application from the Supreme Court which functions as a community service forum for case handling, namely case registration (e-filing), online advance payment (e-Payment), electronic summons (e-Summons) and electronic trials (e-Litigation). at Salatiga District Court in handling that still do not use the references used to manage disasters, so the settlement process does not run optimally. If there is an E-Court incident, it will have an impact on service satisfaction for users. This requires incident management with optimal management in accordance with incident standards. The framework used is ITIL V4 with the main components being a service value system and 4 dimensions, the fourth dimension is the value flow and the process which allows the value stream to have an overview for continuous improvement. The research method uses a qualitative approach that can make it easier to see the condition of incident management at Salatiga District Court. The results of the study were in the form of SOP (Standard Operating Procedure) design as a reference for incident management that occurred, related to the ITIL
\end{abstract}


incident management process, service value chain on ITIL 4 incident management in deliver and support to provide significant contributions and services to the Salatiga District Court incident management.

Keywords - Incident Management, ITIL V4, Service Value System, SOP, Value Stream

\section{PENDAHULUAN}

Teknologi Informasi (TI) memiliki peran dalam memberikan layanan informasi untuk individu, organisasi maupun perusahaan. Pada perusahaan, Sistem Informasi dan Teknologi Informasi (SI TI) dibutuhkan dalam mengelola informasi yang digunakan untuk kelancaran aktivitas operasional dan proses bisnis. Peranan TI sudah menjadi prioritas utama dalam menunjang keberhasilan bisnis, salah satunya adalah layanan TI [1]. Layanan TI pada organisasi bertujuan untuk peningkatan produktivitas dan kualitas, serta menjaga sistem agar tetap dalam keadaan stabil yang jauh dari gangguan atau insiden. Manajemen insiden dapat berdampak besar pada kepuasan pelanggan dan pengguna, dan bagaimana pelanggan dan pengguna memandang penyedia layanan, setiap insiden harus dicatat dan dikelola untuk memastikan bahwa diselesaikan dalam waktu yang memenuhi harapan pelanggan dan pengguna [2]. Dengan adanya penyelesaian insiden yang baik diharapkan tidak terulang lagi sehingga dapat meminimalisir insiden yang sama dikemudian hari. Yang mana perlu diperhatikan agar penyelesaian insiden dapat dilakukan dan layanan dapat dikembalikan dalam keadaan normal secepat mungkin dan mengurangi dampak operasional bisnis yang lebih besar [3]

Pengadilan Negeri Salatiga adalah Pengadilan Negeri (PN) tingkat pertama yang berkedudukan di kota, berfungsi untuk memeriksa, memutus dan menyelesaikan perkara pidana dan perdata bagi masyarakat pencari keadilan. PN Salatiga memiliki aplikasi dari Mahkamah Agung yang sudah terkonfigurasi dan besar dalam menangani perkara seperti salah satunya adalah E-Court, yang diharapkan mampu meningkatkan pelayanan yang fungsinya menerima pendaftaran perkara secara online, sebagai bentuk pelayanan terhadap masyarakat. Dalam hal pendaftaran perkara online (e-filing), pembayaran panjar online (e-Payment), pemanggilan elektronik (e-Summons) dan persidangan elektronik (e-Litigation). Untuk mengetahui pengelolaan insiden telah maksimal, diperlukan untuk mendukung peningkatan dan pembaharuan layanan pada E-Court yaitu analisis incident management E-Court pada PN Salatiga. Untuk memeriksa apakah insiden pada SI TI telah dikelola sesuai dengan keadaan yang terjadi dan bagaimana meminimalkan insiden tersebut dengan baik. Pemecahan masalah suatu insiden dapat disebut incident management [4]. Keuntungan organisasi ketika menerapkan incident management yakni untuk mendeteksi dan menangani kejadian secara lebih dini sehingga mengurangi downtime yang berpengaruh pada bisnis serta menyelaraskan aktifitas TI dengan prioritas bisnis [5]. Dengan adanya penerapan incident management memungkinkan untuk mendukung pemerikasaan, pencatatan, dan penindaklanjutan semua insiden yang dilaporkan oleh pengguna secara efektif [6].

Incident Management adalah Gangguan yang tidak direncanakan ke layanan atau penurunan kualitas layanan. Tujuannya untuk meminimalkan dampak negatif dengan memulihkan operasi layanan secepat mungkin [2]. Sekaligus memastikan bahwa tahapan yang paling baik dari kualitas layanan dan ketersediaannya [7]. Untuk mengelola insiden pada layanan, diperlukan kerangka kerja yang dapat mengelola sumber sistem informasi yang ada, seperti kerangka kerja yang sering dipakai adalah COBIT dan ITIL. Adapun untuk penelitian ini menggunakan kerangka kerja ITIL (Information Technology Infrastructure Library). Dalam hal ini ITIL sangat tepat digunakan sebagai panduan dalam mengembangkan sebuah teknis

Ayuh, et., al [Analisis Incident Management E-Court pada Pengadilan Negeri Salatiga Menggunakan 
pelaksanaan, yang sifatnya best practice untuk mengembangkan langkah-langkah dalam prosedur. Prosedur yang dilakukan berulang yang telah terbukti berhasil digunakan oleh banyak pihak untuk dalam jangka waktu yang cukup lama [8]. ITIL sebagai kerangka kerja yang dijadikan pedoman dalam penerepan manajemen layanan teknologi informasi [9]. Pada penelitian ini menggunakan ITIL V4

ITIL V4 merupakan ITIL versi terbaru dengan pembaharuan banyak praktik ITSM (Information Technology Service Management) manajemen layanan teknologi informasi yang lebih luas, dalam memperhatikan pengalaman pelanggan, value stream dan transformasi digital, mengadopsi cara kerja seperti Lean, Agile, dan DevOps. Komponen utama ITIL V4 adalah ITIL service value system (SVS) dan pada tatakelola IT kerangka kerja ITIL V4 juga menggunakan service value chain sebagai siklus hidup implementasinya [10]. ITIL V4 memberikan panduan yang dibutuhkan organisasi untuk menangani layanan baru mengelola tantangan dan memanfaatkan potensi teknologi modern yang dirancang untuk memastikan sistem fleksibel, terkoordinasi dan terintegrasi agar tata kelola dan manajemen layanan yang mendukung TI. 26 proses pada ITILV3 telah ditambah dan diganti menjadi 34 practice, pada salah satu practice yang menyediakan manajemen yang berdampak besar pada penyedia layanan dan pengguna yaitu incident management dalam hal ini manajemen yang tepat dalam alokasi sumber daya untuk berbagai jenis insiden. [2]

Tujuan dari penelitian ini adalah bagaimana pengelolaan incident management yang tepat pada salah satu aplikasi dari Mahakamah Agung di PN Salatiga yaitu E-Court sesuai dengan sumber yang ada, sehingga dapat memberikan layanan yang optimal dalam pengelolaan incident pada E-Court, serta mengetahui sejauh mana pengelolaan incident yang diterapkan. Adapun penelitian mencangkup analisa proses incident yang diterapkan pada PN Salatiga dengan aktivitas value chain pada ITILV4, dan perbandingan tahapan incident keadaan sekarang dengan incident management ITIL, SOP incident managemet yang sekiranya dapat dipakai serta untuk meningkatkan manajemen insiden pada PN Salatiga

\section{METODE PENELITIAN}

Penelitian ini menggunakan pendekatan kualitatif dalam mengolah dan menganalisa data pada E-Court PN Salatiga. Yang meliputi pengumpulan data, olah data, analisa untuk melihat gambaran mengenai incident management dengan kerangka kerja ITIL V4 pada aktivitas service value chain.

\subsection{Dasar Teori}

Penelitian ini menggunakan kerangka kerja ITIL V4. Komponen utama dari kerangka kerja ITIL V4 adalah ITIL service value system dan 4 model dimensi. ITIL SVS mereprentasikan bagaimana berbagai komponen dan aktivitas organisasi bekerja sama untuk memfasilitasi penciptaan nilai melalui layanan yang mendukung TI. Komponen inti dari ITIL SVS adalah Service Value Chain, rangkaian kegiatan yang saling berhubungan yang organisasi bekerja untuk memberikan produk atau layanan yang berharga kepada komsumennya dan kepada untuk memfasilitasi realisasi nilai. ITIL Practices, sumber daya organisasi yang dirancang untuk melakukan pekerjaan atau mencapai tujuan, pada ITIL V4 terdapat 34 practice, practice yang digunakan pada penlitian Incident management. Guiding Principle, prinsip prinsip panduan rekomendasi yang dapat memandu organisasi secara keadaan keseluruhan, terlepas dari perubahan dalam tujuan, strategi, jenis pekerjaan atau struktur manajemen. Governance, dimana organisasi diarahkan dan dikendalikan. Continual Imporvement, kegiatan organisasi berulang dilakukan disemua tingkatan untuk memastikan bahwa kinerja organisasi terus memenuhi harapan pemangku kepentingan. Tujuan SVS adalah untuk memastikan bahwa organisasi terus menciptakan nilai bersama dengan semua pemangku kepentingan melalui

Ayuh, et., al [Analisis Incident Management E-Court pada Pengadilan Negeri Salatiga Menggunakan 
penggunaan dan pengelolaan product and service Struktur SVS ITIL seperti pada Gambar 1. Sisi kiri gambar menunjukkan peluang dan permintaan yang masuk ke dalam SVS baik dari sumber internal maupun eksternal. Sisi kanan menunjukkan nilai yang diciptakan untuk organisasi, pelanggannya dan pemangku kepentingan lainnya.

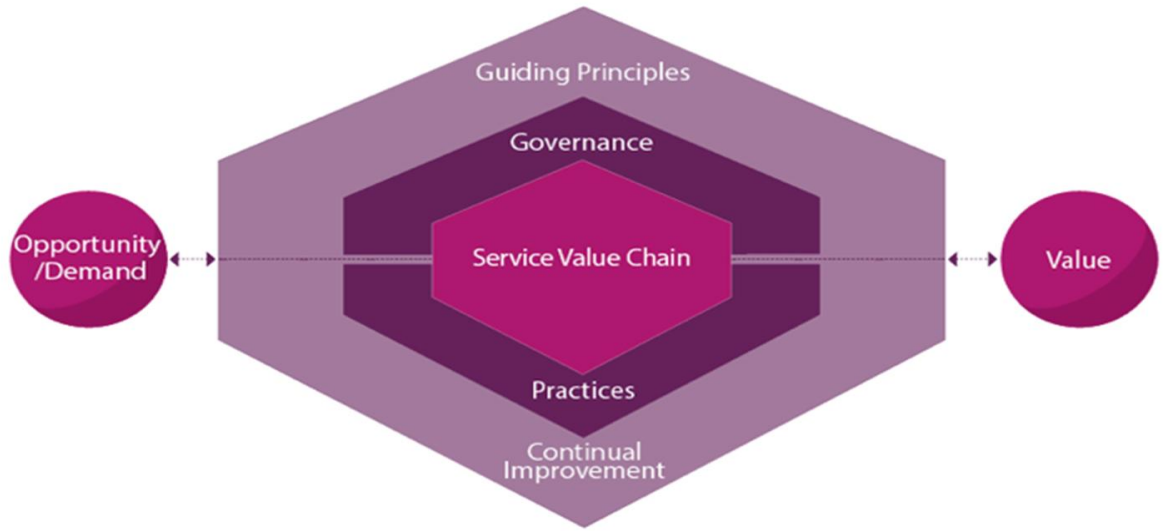

Gambar 1. ITIL Service Value System [3]

Untuk memastikan pendekatan holistik untuk manajemen layanan, ITIL V4 menguraikan dimensi manajemen layanan, dari mana setiap komponen SVS harus mempertimbangkan keempat dimensi tersebut adalah organization and people, information and technology, partners and suppliers, value stream and processes. Elemen sentral dari SVS adalah service value chain Seperti Gambar 2 dibawah ini.

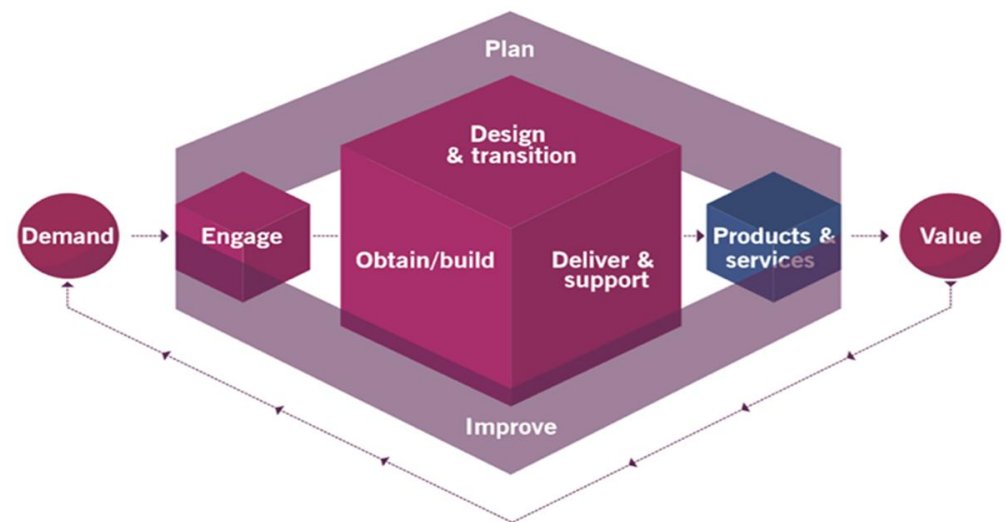

Gambar 2. ITIL Service Value Chain [3]

Gambar 2 diatas yaitu model operasi yang menguraikan kegiatan utama yang diperlukan untuk menanggapi demand dan memfasilitasi realisasi melalui penciptaan dan pengelolaan product and service. 


\section{2 Tahapan Penelitian}

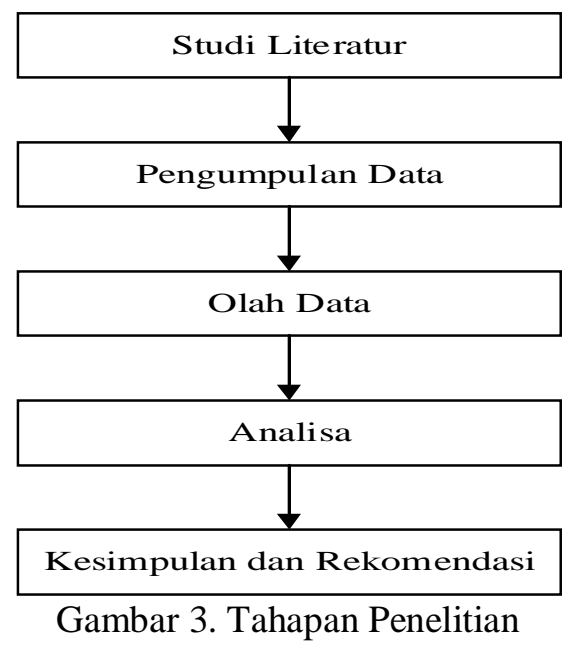

Pada tahap pertama yaitu studi literatur yang bersumber dari $e$-book dan jurnal nasional, maupun sumber ilmiah lainnya membahas mengenai incident management dan ITIL V4 untuk membantu memahami dan mendukung penelitan. Tahap kedua pengumpulan data menggunakan pendekatan kualitatif meliputi observasi dimana pengamatan langsung selama 2 bulan, wawancara dengan pihak yang bersangkutan untuk menambah data yang diperlukan, wawancara dengan pihak terkait menggunakan pertanyaan yang mengacu pada fokus penelitian ini yaitu incident management. Narasumber wawancara adalah user juga sekaligus Admin eCourt pada PN salatiga dan staff bagian infrastruktur TI pada PN Salatiga. Tahap ketiga olah data yang diperoleh dari wawancara dan pengamatan langsung mengenai manajemen yang diterapkan digunakan untuk diolah menjadi informasi yang relevan. Tahapan keempat proses analisis dari pengolahan data berdasarkan informasi yang didapat untuk mendapatkan keadaan aktivitas dalam proses manajemen insiden pada PN Salatiga. Serta membandingkan kontribusi incident management ITIL V4 pada service value chain dengan proses pengelolaan incident pada PN Salatiga, dan perbandingan tahapan incident keadaan sekarang dengan incident management ITIL. Pada tahapan terakhir temuan yang didapat berdasarkan analisis dapat ditarik kesimpulan, dan usulan SOP incident management.

\section{HASIL DAN PEMBAHASAN}

Berdasarkan hasil wawancara dan observasi, pada bagian kepaniteraan dan bagian kesekretariatan PN salatiga masing-masing memiliki staff dalam menangani incident yang terjadi, tidak hanya pada E-Court, juga pada aplikasi lainnya. Tetapi penyelesaian saat ini belum memenuhi kebutuhan manajemen layanan TI. Setiap incident yang terjadi pada user mengenai E-Court akan ditangani pada bagian tersebut yakni salah satunya staff TI dan admin e-Court. Jika terjadi incident, pada bagian kepaniteraan yang menangani adalah user sekaligus admin ECourt. Begitu juga dibagian kesekretariatan yang menangani yakni staff pengelola infrastruktur TI. Saat terjadi incident pada user PN salatiga, staff TI/admin e-Court langsung bertemu user untuk mengecek kembali keadaan incident yang terjadi untuk bagaimana penyelesainnya incident, yang terlebih dahulu diidentifikasi sesuai pengetahuan dan pengalamam staff TI/admin E-Court. Penyampaian dari setiap incident yang terjadi atau permintaan layanan disampaikan dengan media grup whatsapp Tim IT Jateng sebagai laporan jika tidak ada solusi dari staff IT 
dan admin e-Court PN Salatiga. Untuk pelaporan incident hanya sebatas penyampaian saja dan belum memiliki prosedur incident management yang sesuai dengan standar manajemen layanan.

Pada PN Salatiga terdapat meja layanan E-Court sebagai service desk dan wadah komunikasi serta konsultasi untuk penyedia layanan dengan pengguna luar atau masyarakat luar. Tetapi belum adanya pengelolaan incident yang terkontrol dan diselesaikan dalam jangka waktu yang ditentukan dan blum adanya prosedur mengatur tentang incident yang terjadi. Yang mana tidak adanya pencatatan incident, dokumentasi, progres incident, waktu penyelesaian dan laporan tersebut sudah selesai ditangani untuk dijadikan referensi jika terjadi incident yang sama. Yang mengakibatkan membuat para staff TI dan admin E-Court menyadari bahwa perlunya peningkatan manajemen insiden pada E-Court yang mana proses penanganannya masih kurang. Untuk mendukung koordinasi pada Tim TI dan IT Develop jika terjadi incident layanan yang digunakan untuk komunikasi dan laporan yaitu melalui Whatsapp, Telegram, email. Media tersebut digunakan untuk saling bertukar informasi dengan staff TI/admin E-Court pada pihak PN daerah lain. Untuk pertemuan rutin antara pihak staff TI/admin E-Court dan Tim TI/IT Develop hanya dilakukan dengan koordinasi dan laporan secara lisan melalui media tersebut.

Pengelolaan layanan incident management pada PN Salatiga belum memiliki SOP (Standard Operating Procedure). Untuk penggunaan dan pengelolaan data E-Court terdapat SOP yang mendukung. Mengenai maintenance operasional TI pada E-Court dilakukan setahun 2 kali, sedangkan kegiatan backup database dilakukan 2 kali dalam 1 hari yaitu pada jam 8 pagi dan 4 sore serta monitoring dilakukan oleh administrator E-Court. Pada E-Court PN Salatiga terdapat history incident yang terjadi tetapi belum terdeteksi secara otomatis pada sistem. Pada ruang server belum dilengkapi dengan security sistem untuk perlindungan dari pihak yang tidak berwenang misalnya berupa fingerprint dan juga tidak dilengkapi CCTV serta alat pendeteksi kebakaran. Saat ini untuk incident management pada PN Salatiga hanya sekedar dikelola apabila mungkin terjadi, yang belum mengacu pada standar incident management. Belum pernah dilakukan penilaian tentang kepuasan pengguna terhadap kualiatas layanan E-Court pada PN Salatiga. Namun untuk memiliki pengelolaan incident management masih belum menyadari bahwa menjadi kebutuhan organisasi untuk mendukung manajemen layanan TI, agar dapat memberikan kualitas layanan yang berkualitas sehingga dapat meningkatkan pelayanan yang optimal.

Berikut adalah daftar incident yang pernah terjadi pada E-Court di PN Salatiga dalam jangka waktu belakang ini dari hasil wawancara pada Staff infrastruktur IT dan Administrator eCourt.

Tabel 1. Daftar Incident E-Court yang Pernah Terjadi pada PN Salatiga

\begin{tabular}{|l|l|l|}
\hline \multicolumn{1}{|c|}{$\begin{array}{c}\text { Indikasi } \\
\text { incident }\end{array}$} & \multicolumn{1}{|c|}{ Resiko incident } & \multicolumn{1}{c|}{ Dampak } \\
\hline $\begin{array}{l}\text { Server error, } \\
\text { Trafic user full }\end{array}$ & $\begin{array}{l}\text { User kesulitan login pada E- } \\
\text { Court }\end{array}$ & $\begin{array}{l}\text { Bila user kesulitan login pada sistem } \\
\text { berdampak aktivitas user dalam } \\
\text { penanganan pekara yang masuk }\end{array}$ \\
\hline $\begin{array}{l}\text { e-Payment } \\
\text { trouble }\end{array}$ & $\begin{array}{l}\text { Virtual Accont/ briva tidak bisa } \\
\text { dibayar }\end{array}$ & $\begin{array}{l}\text { Dampak user/ pengguna dari } \\
\text { masyarakat umum adalah menghambat } \\
\text { proses transaksi }\end{array}$ \\
\hline Sistem error & $\begin{array}{l}\text { Tertukarnya data perkara PN } \\
\text { Salatiga dengan data perkara } \\
\text { PN lain }\end{array}$ & $\begin{array}{l}\text { Berdampak pada keberlangsungan/ } \\
\text { menghambat proses perkara yang sudah } \\
\text { masuk pada sistem }\end{array}$ \\
\hline Server down & $\begin{array}{l}\text { E-Court tidak dapat diakses } \\
\text { oleh } \text { user }\end{array}$ & $\begin{array}{l}\text { Bila user kesulitan login pada sistem } \\
\text { berdampak aktivitas user dalam }\end{array}$ \\
\hline
\end{tabular}

Ayuh, et., al [Analisis Incident Management E-Court pada Pengadilan Negeri Salatiga Menggunakan 


\begin{tabular}{|l|l|l|}
\hline Sistem trouble & $\begin{array}{l}\text { Tidak dapat menandatangani } \\
\text { dokumen secara elektronik } \\
\text { signiture } \text { ) }\end{array}$ & $\begin{array}{l}\text { Menghambat proses aktivitas dalam } \\
\text { penanganan pekara }\end{array}$ \\
\hline Sistem error & $\begin{array}{l}\text { Ketika input data perkara } \\
\text { permohonan pada sistem data } \\
\text { yang masuk berubah menjadi } \\
\text { data gugatan }\end{array}$ & $\begin{array}{l}\text { Berdampak pada keberlangsungan/ } \\
\text { menghambat proses perkara yang sudah } \\
\text { masuk pada sistem }\end{array}$ \\
\hline Sistem error & $\begin{array}{l}\text { Terkuncinya tombol untuk } \\
\text { verifikasi berkas }\end{array}$ & $\begin{array}{l}\text { Menghambat proses aktivitas dalam } \\
\text { penanganan pekara }\end{array}$ \\
\hline
\end{tabular}

Gambar 4 Kontribusi incident management ke service value chain dengan practice yang diterapkan terutama pada engage dan pada deliver and support pada aktivitas value chain. Proses ini tidak mencakup prosedur rinci tentang cara mendiagnosis, menyelidiki, dan menyelesaikan insiden, tetapi dapat memberikan teknik untuk melakukan investigasi dan diagnosis lebih efisien. Berhadapan dengan insiden memungkinkan dalam setiap aktivitas rantai nilai, meskipun yang paling terlihat adalah insiden di lingkungan operasional. Karena pengaruhnya terhadap pengguna.

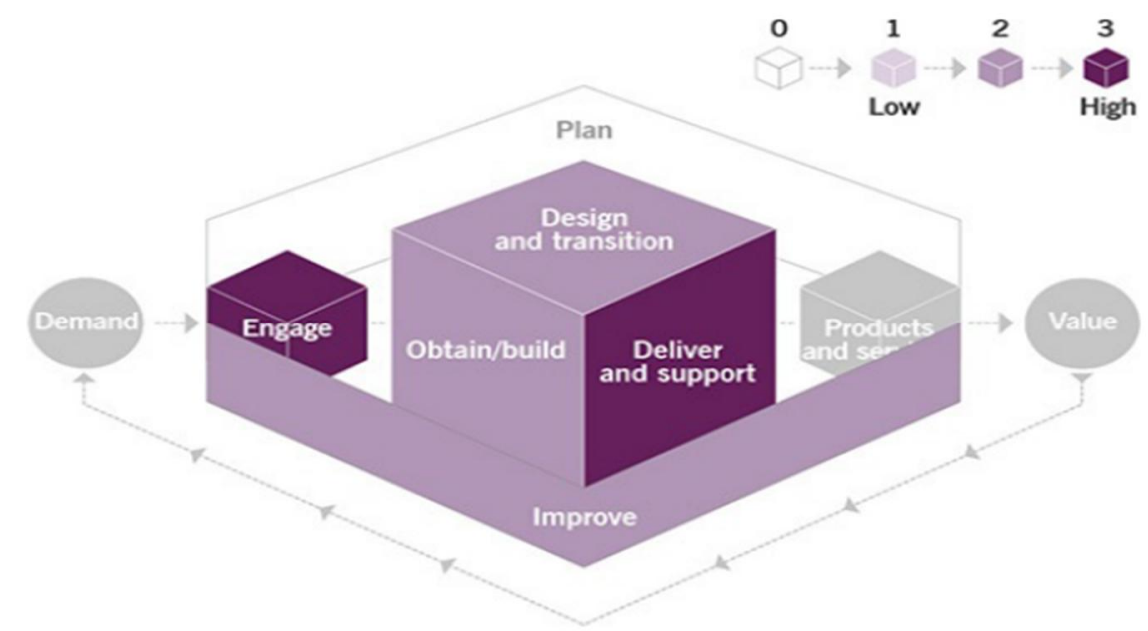

Gambar 4. Kontibusi Incident Mangement ITIL V4 pada Aktivitas Service Value Chain

Penjelasan disetiap Aktivitas Service Value Chain

Improve, Memperbaiki catatan insiden merupakan hal utama untuk kegiatan perbaikan dan yang sedang diprioritaskan dengan baik sesuai dengan frekuensi dan tingkat keparahan insiden. Engage, Keterlibatan insiden dapat dilihat oleh pengguna, dan insiden yang signifikan juga dapat dilihat oleh pelanggan. Manajemen yang baik membutuhkan insiden yang baik dan membutuhkan komunikasi yang teratur untuk memahami masalah, menetapkan ekspetasi, memberikan pembaharuan status, dan menyetujui bahwa masalah tersebut telah diselesaikan sehingga insiden dapat ditutup. Design and Transition, Desain dan Transisi insiden dapat terjadi di lingkungan pengujian, serta selama dirilis dan penerapan layanan. Praktik ini memastikan insiden yang terjadi ini diselesaikan secara tepat waktu dan terkontrol. Obtain/Build, Memperoleh/Membangun insiden dapat terjadi di lingkungan pengembangan. Practices incident management ini diselesaikan secara tepat waktu dan terkontrol. Deliver and Support, Menyampaikan dan Mendukung manajemen insiden memberikan kontribusi yang signifikan kepada support. Aktivitas value chain ini mencangkup penyelesaian insiden dan masalah. 
Tabel 2 dibawah menunjukkan bagaimana practice incident management mendukung value stream pada service value system. Mengidentifikasi dan memahami berbagai value stream yang dimiliki organisasi penting untuk meningkatkan kinerjanya secara keseluruhan. Penataan aktivitas organisasi dalam bentuk value stream memungkinkannya memiliki gambaran yang jelas tentang apa yang diberikannya dan bagaimana, duntuk melakukan perbaikan terus-menerus pada layanannya.

Tabel 2. Value Stream Incident Management ITIL 4 pada PN Salatiga

\begin{tabular}{|c|c|c|c|}
\hline $\begin{array}{c}\text { Value chain } \\
\text { activity/input/ } \\
\text { outcomes }\end{array}$ & Practice & Roles & Activities \\
\hline Improve & $\begin{array}{c}\text { Incident } \\
\text { Management }\end{array}$ & $\begin{array}{l}\text { Service Desk } \\
\text { Admin } \\
\text { E-Court } \\
\text { Tim IT, }\end{array}$ & $\begin{array}{l}\text { - Pada PN Salatiga belum ada pencatatan } \\
\text { sebagai dokumentasi penyelesaian pada } \\
\text { incident yang pernah terjadi pada tabel } 2 \text {. }\end{array}$ \\
\hline Engage & $\begin{array}{c}\text { Incidet } \\
\text { management }\end{array}$ & $\begin{array}{l}\text { Admin } \\
\text { E-Court, } \\
\text { Tim IT }\end{array}$ & $\begin{array}{l}\text { - User PN Salatiga memberitahu kepada } \\
\text { Admin E-Court, bahwa user kesulitan } \\
\text { login pada sistem E-Court, dan ketika } \\
\text { login sistem otomatis ter logout. Admin } \\
\text { mendengarkan incident tersebut secara } \\
\text { lisan. Kesulitan login terjadi 10x dalam } \\
\text { sebulan menurut wawancara pada admin } \\
\text { E-Court } \\
\text { - Admin E-Court menyampaikan kepada } \\
\text { grup Tim IT Se-Jateng melalui media } \\
\text { whatsapp. Tidak adanya pencatatan dari } \\
\text { Pihak admin Sebagai dokumentasi, } \\
\text { maupun ketika disampaikan pada Tim IT. }\end{array}$ \\
\hline $\begin{array}{l}\text { Design and } \\
\text { Transition }\end{array}$ & $\begin{array}{c}\text { Incident } \\
\text { Management }\end{array}$ & $\begin{array}{c}\text { Admin } \\
\text { E- Court, } \\
\text { Staff TI }\end{array}$ & $\begin{array}{l}\text { - Jika dalam waktu lama sistem masih } \\
\text { dalam keadaan sulit login dan saat login } \\
\text { sistem ter logout otomatis. User hanya } \\
\text { perlu mendiamkan sejenak atau } \\
\text { menggunakan komputer lain, dan } \\
\text { mencoba sampai kira-kira sistem dalam } \\
\text { keadaan stabil sehingga bisa login } \\
\text { kembali. } \\
\text { - Admin E-Court memberikan penjelasan } \\
\text { secara lisan kepada user bahwa yang } \\
\text { terjadi dikarenakan traffic user penuh. } \\
\text { Tindakan yang diambil yaitu } \\
\text { mendiamkan sistem sejenak dan mencoba } \\
\text { login kembali. Biasanya waktu traffic full } \\
\text { pada jam tertentu. }\end{array}$ \\
\hline Obtain/Build & $\begin{array}{c}\text { Incident } \\
\text { Management }\end{array}$ & $\begin{array}{c}\text { Admin } \\
\text { E-Court, } \\
\text { TIM TI,IT }\end{array}$ & $\begin{array}{l}\text { - Maintenance pada e-Court dilakukan } 2 \text { x } \\
\text { dalam setahun } \\
\text { - sedangkan kegiatan backup database }\end{array}$ \\
\hline
\end{tabular}




\begin{tabular}{|c|c|c|c|}
\hline & & Develop & $\begin{array}{l}\text { dilakukan } 2 \text { kali dalam } 1 \text { hari yaitu pada } \\
\text { jam } 8 \text { pagi dan } 4 \text { sore serta monitoring } \\
\text { dilakukan oleh administrator e-Court. Hal } \\
\text { ini tidak menutup kemungkinan jika } \\
\text { incident terjadi }\end{array}$ \\
\hline $\begin{array}{l}\text { Deliver and } \\
\text { Support }\end{array}$ & $\begin{array}{c}\text { Incident } \\
\text { Management }\end{array}$ & $\begin{array}{l}\text { Service } \\
\text { Desk, } \\
\text { Tim TI, } \\
\text { Admin } \\
\text { E-Court }\end{array}$ & $\begin{array}{l}\text { - Jika terdapat incident pada PN salatiga } \\
\text { mengenai aplikasi E-Court, dapat } \\
\text { disampaikan melalui media grup Tim IT } \\
\text { Se-jateng oleh admin E-Court } \\
\text { - Belum adanya panduan untuk pengaduan } \\
\text { insiden yang terjadi dan proses } \\
\text { penyelsesainya. Selama ini hanya } \\
\text { menggunakan media whatsapp untuk } \\
\text { diskusi dan mengkoordinasi penanganan } \\
\text { incident tersebut. }\end{array}$ \\
\hline
\end{tabular}

Dalam pengelolaan incident ntuk menjaga layanan TI sesuai dengan kebutuhan pengguna sebagai yang mengelola layanan pada PN Salatiga yakni staff TI/admin E-Court harus meningkatkan layanan TI yang sudah ada. Sehingga proses penanganan dilakukan secara optimal. Tetapi belum ada proses manajemen layanan TI yang diterapkan secara keseluruhan. Dapat dilihat pada Tabel 3 dibawah.

Tabel 3. Proses Incident Management ITIL vs Penanganan Insiden pada PN Salatiga

\begin{tabular}{|l|l|}
\hline \multicolumn{1}{|c|}{$\begin{array}{c}\text { Tahapan Incident } \\
\text { Management }\end{array}$} & \multicolumn{1}{c|}{ Keadaan Saat Ini } \\
\hline Incident Identification & $\begin{array}{l}\text { Untuk identifikasi insiden belum ada penjelasan atau diagnosa } \\
\text { bahwa gangguan yang dilaporkan adalah insiden pada layanan } \\
\text { IT. Laporan incident melalui telepon, whatsapp email, dan } \\
\text { datang langsung pada PN salatiga dan dapat disampaikan di } \\
\text { meja layanan E-Court }\end{array}$ \\
\hline Incident Logging & $\begin{array}{l}\text { Belum adanya ketentuan pencatatan incident pada PN Salatiga, } \\
\text { petugas/staff yang melayani mendengarkan dan menyampaikan } \\
\text { pada staff TI/admin E-Court, serta belum adanya riwayat } \\
\text { insiden yang sudah terselesaikan sebelumnya. }\end{array}$ \\
\hline Incident Categorization & $\begin{array}{l}\text { Pengkategorian insiden E-Court pada PN Salatiga masih belum } \\
\text { ada, sesuai keadaan dengan standar menurut staff IT/admin E- } \\
\text { Court. }\end{array}$ \\
\hline Incident Priorization & $\begin{array}{l}\text { Belum adanya penentuan prioritas insiden yang terjadi pada PN } \\
\text { Salatiga sesuai dengan panduan manajemen layanan TI , staff/ } \\
\text { admin E-Court hanya menerka-nerka . }\end{array}$ \\
\hline Incident Diagnosis & $\begin{array}{l}\text { Petugas hanya menerka-nerka insiden yang disampaikan dari } \\
\text { user berdasarkan analisis dan pengalaman serta pengetahuan } \\
\text { yang diketahui oleh staff IT/admin E-Court }\end{array}$ \\
\hline \multirow{2}{*}{ Incident Escalation } & $\begin{array}{l}\text { Insiden yang terjadi terkait server / sistem di tangani oleh pihak } \\
\text { Develop IT laporan disampaikan pada grup TIM TI Se-Jateng, } \\
\text { Jika belum dapat penyelesaiannya disampaikan melalui grup } \\
\text { Koordinasi IT MA Se-Indonesia. Dan belum ada target waktu } \\
\text { dalam penyelesaian insiden, staff TI/admini E-Court hanya } \\
\text { menunggu informasi dari pengadilan tinggi melalui media grup } \\
\text { whatsapp ketika sistem pada E-Court sudah kembali dalam }\end{array}$ \\
\hline
\end{tabular}




\begin{tabular}{|l|l|}
\hline & keadaan stabil \\
\hline $\begin{array}{l}\text { Investigation and } \\
\text { Diagnosis }\end{array}$ & $\begin{array}{l}\text { Pada tahapan ini diagnosa insiden dilakukan pada Tim Develop } \\
\text { dari MA. Belum adanya status penanganan insiden yang } \\
\text { berjalan, ketika terjadi incident staff TI/admin E-Court yang } \\
\text { mengelola hanya menunggu update terkait insiden } t \text { yang terjadi } \\
\text { pada sistem }\end{array}$ \\
\hline Resolution and Recovery & $\begin{array}{l}\text { Penyelesaian insiden sudah sesuai, dengan melakukan pengujian } \\
\text { dan pengecekkan kembali sistem pada E-Court oleh Tim IT } \\
\text { tetapi belum ada pengelolaan insiden yang dilakukan, semua } \\
\text { proses penyelesaian disampaikan melalui grup whatsapp untuk } \\
\text { komunikasi }\end{array}$ \\
\hline Incident Closure & $\begin{array}{l}\text { Proses penutupan insiden hanya penyampaian kepada user } \\
\text { bahwa sistem sudah optimal dan dapat dioperasikan kembali }\end{array}$ \\
\hline
\end{tabular}

Untuk mengelola incident management agar layanan tetap baik bagi pengguna sebagai staff IT dan administrator E-Court pada PN Salatiga harus memberikan layanan untuk memaksimalkan proses mengelolaan incident yang sudah diterapkan agar lebih terstruktur [11]. 


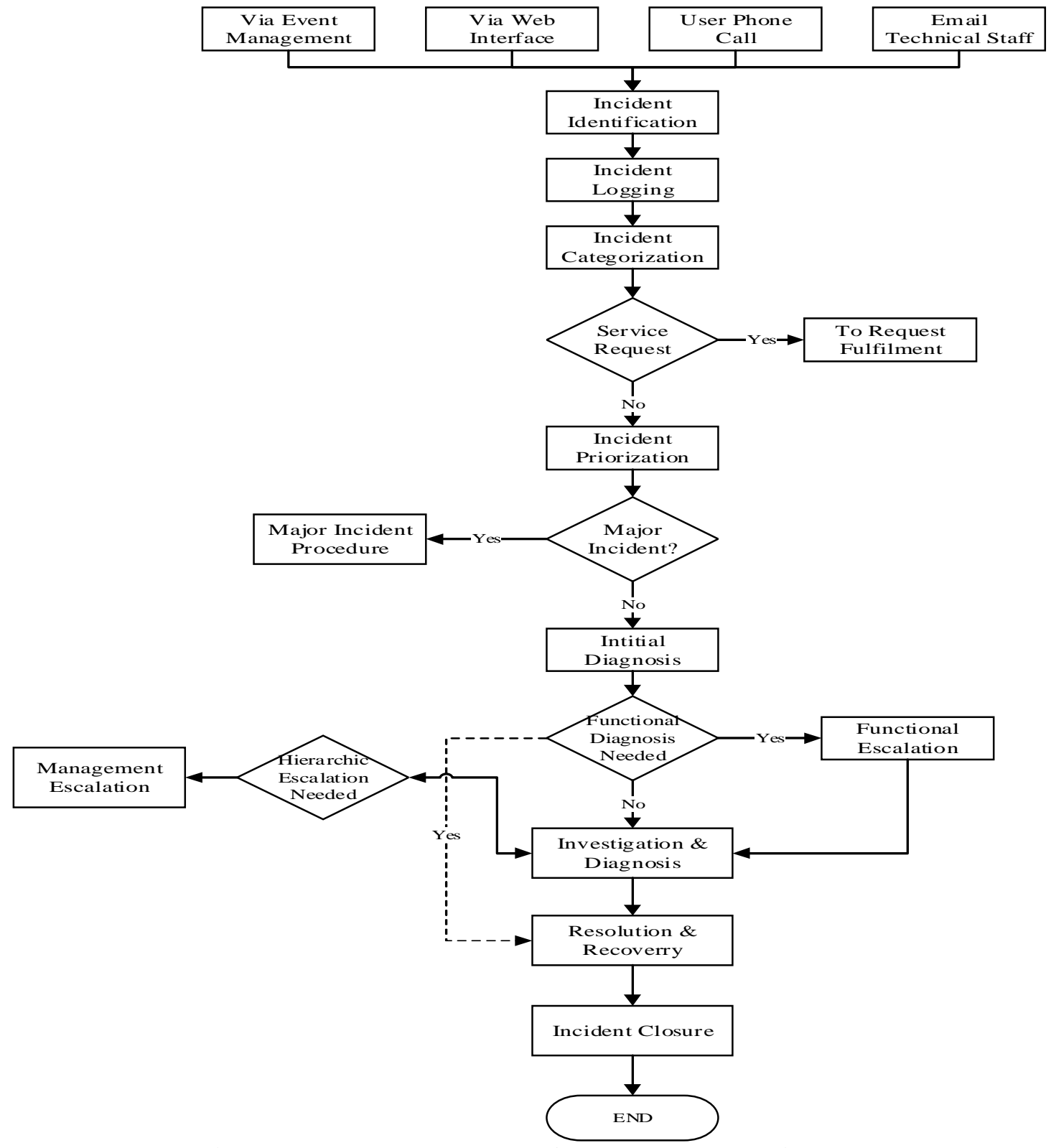

Gambar 5. Proses Penanganan Incident Management pada ITIL [5]

SOP (Standard Operating Procedure) pada gambar 6 dibawah disusun sebagai acuan untuk pengelolaan incident yang terjadi. Yang berkaitan pada proses incident management ITIL dan service value chain pada incident management ITIL 4 dalam deliver dan support untuk memberikan kontribusi dan layanan yang signifikan pada incident management PN Salatiga. Yang mana service value chain mencakup penyelesaian insiden. 


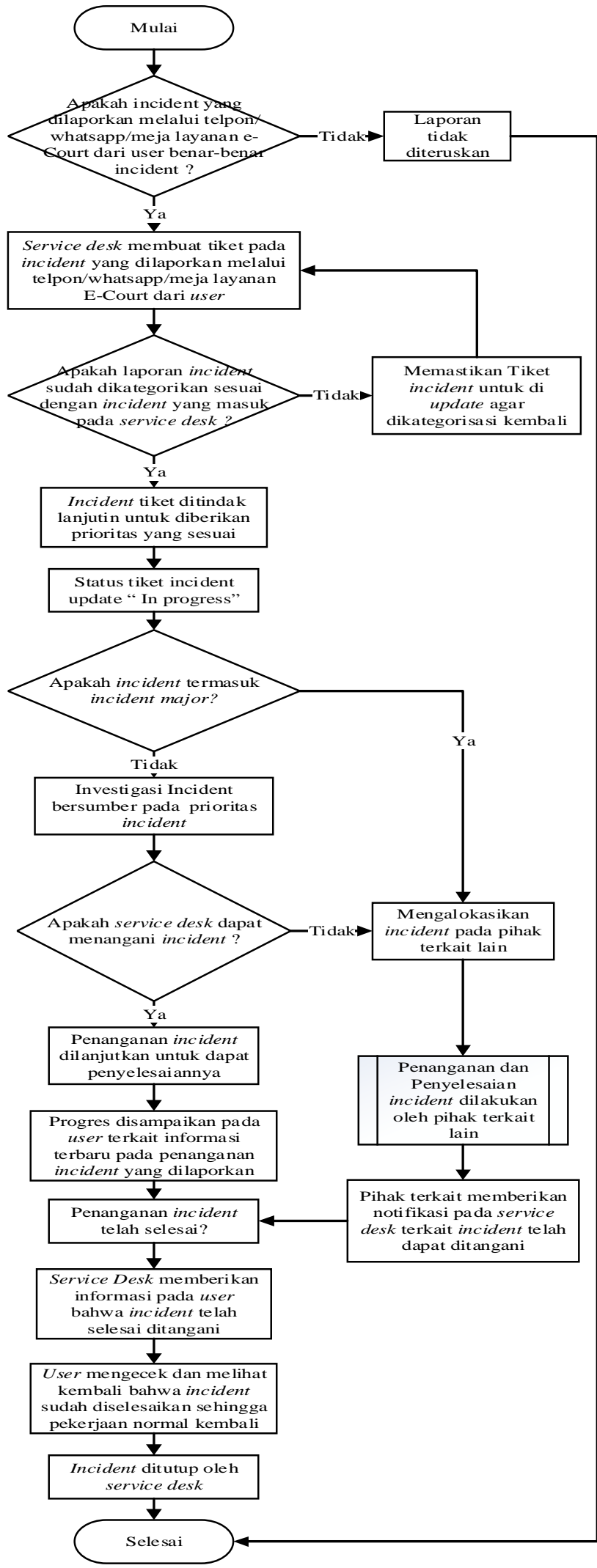

Gambar 6. Penyusunan SOP Penanganan Incident Management pada PN Salatiga

Ayuh, et., al [Analisis Incident Management E-Court pada Pengadilan Negeri Salatiga Menggunakan Framework ITIL V4 


\section{KESIMPULAN}

Berdasarkan penelitian yang dilakukan analisis pada incident management PN Salatiga, dapat disimpulkan bahwa PN Salatiga belum memenuhi kebutuhan manajemen layanan TI dalam penanganan incident. Akan tetapi insiden yang terjadi telah di selesaikan. Penanganan insiden yang belum memberikan layanan secara maksimal dapat berpengaruh pada aktivitas operasional user E-Court PN Salatiga dan user pengguna luar. Hal ini menyebabkan proses penanganan kurang optimal, seperti belum ada pencatatan insiden, penentuan prioritas, pengelompokan insiden, progres insiden. Dan dapat ditarik kesimpulan bahwa PN salatiga belum sepenuhnya menerapkan incident management ITIL V4 pada aktivitas value chain, deliver and support yakni Tim IT belum memberikan kontribusi yang signifikan untuk mendukung incident management pada PN salatiga. Seperti insiden dari user pengguna luar atau masyarakat umum yaitu tertukarnya data perkara yang masuk pada E-Court PN Salatiga dengan data perkara PN lain. Hal ini membuat staff IT/admin E-Court kesulitan dalam penanganan untuk proses investigasi dan pemantauan insiden yang terjadi. Mereka menyadari bahwa bisa mempersiapkan seperti melakukan peningkatan atau mengalokasikan langsung yang masuk dalam major incident. Sehingga user pengguna luar dapat mengetahui sampai mana proses penyelesaian insiden dan tidak terkesan seperti menunggu tidak kejelasan tahapan insiden tersebut. PN salatiga menyadari bahwa incident management adalah hal penting untuk ditingkatkan dalam menangani insiden yang berpotensi akan terjadi. Sehingga dapat diusulkan proses penanganan insiden sesuai dengan incident management ITIL dan Penyusunan SOP dapat mendukung penanganan incident management sekaligus membantu proses penyelesaian incident PN Salatiga.

\section{SARAN}

Penelitian selanjutnya dapat dikembangkan dalam menggunakan kerangka kerja terbaru ITIL V4. Agar implementasi practice pada ITIL V4 dapat dijalankan secara menyeluruh. Dan penelitian selanjutnya menggunakan metode lain seperti metode kuantatif untuk mengukur matrix dan dapat menggunakan practice incident management dengan practice lain seperti problem management.

\section{DAFTAR PUSTAKA}

[1] M. A. Pratiwi and A. R. Tanaamah, "Analysis of IT Service Management in The Salatigaku Application Using The Framework Information Technology Infrastructure Library (ITIL) V3,” J. Inf. Syst. Informatics, Vol. 2, No. 1, pp. 33-43, 2020, doi: 10.33557/journalisi.v2i1.38.

[2] Axelos, ITIL Foundation: ITIL 4 Edition, No. 1. London, England, 2019.

[3] A. B. Febriant, Y. T. Mursityo, and A. Rachmadi, "Evaluasi Maturity Level Manajemen Layanan Teknologi Informasi Menggunakan Framework Itil V3 Domain Service Operation pada 24Slides Corporation," J. Pengemb. Teknol. Inf. dan Ilmu Komput., Vol. 3, No. 6, pp. 5608-5615, 2019.

[4] V. R. Palilingan and J. R. Batmetan, "Incident Management in Academic Information System Using ITIL Framework,” IOP Conf. Ser. Mater. Sci. Eng., Vol. 306, No. 1, pp. 0-9, 2017, doi: 10.1088/1757-899X/306/1/012110. 
[5] D. Rahman Wijaya, "Usulan Incident Management Menggunakan IT Infrastructure Library version 3 (Studi Kasus Politeknik Telkom) Mobile Electronic Nose (MoLen) View Project," Vol. 3, No. May, 2013, [Online]. Available: https://www.researchgate.net/publication/277306770.

[6] A. S. Anandityo and Y. T. Mursityo, "Evaluasi Incident Management dan Problem Management Sistem Informasi Manajemen Rumah Sakit (SIMRS) pada Rumah Sakit Umum Daerah Kanjuruhan Kabupaten Malang Menggunakan Framework ITIL V3," Vol. 3, No. 10, p. 3, 2019.

[7] S. Susilowati, "Evaluasi Tata Kelola Teknologi Informasi pada Area Service Operation Menggunakan Kerangaka Kerja ITIL Versi 3 (Studi Kasus: pada Dinas Komunikasi dan Informasi Kota Depok)," Paradigma, Vol. XIV, No. 2, pp. 131-140, 2012.

[8] N. F. Annisa, A. P. Kurniati, S. Y. Puspitasari, and F. Informatika, "Analisis Penilaian Kesiapan \& Implementasi Sistem Informasi B-m@x dengan ITIL Versi 3 pada Domain Service Transition \& Service Operation) Studi Kasus PT.PLN Regional Jawa Barat dan Banten,” e-Proceeding Eng., Vol. 1, No. 1, pp. 601-606, 2014.

[9] W. Asih Paramesti, Y. Tyroni Mursito, and A. Racmadi, "Evaluasi Incident Management dan Problem Management pada Bank Mandiri Unit Electronic Channel Operations (Eco) Region Ix Kalimantan Menggunakan Framework Itil V3 Domain Service Operation," J. Pengemb. Teknol. Inf. dan Ilmu Komput. Univ. Brawijaya Pengemb. Teknol. Inf. dan Ilmu Komput., Vol. 3, No. 9, pp. 8487-8495, 2019.

[10] M. A. Aditya, R. D. Mulyana, and A. Mulyawan, "Perbandingan Cobit 2019 Dan Itil V4 Sebagai Panduan Tata Kelola dan Management It,” J. Comput. Bisnis, Vol. 13, No. 2, pp. 100-105, 2019.

[11] I. Menken, G. Blokdijk, and C. Engle, The ITIL V3 Factsheet Benchmark Guide: An Award-Winning ITIL Trainers Tips On Achieving ITIL V3 and ITIL Foundation Certification For ITIL Service Management. 2009. 